\title{
High correlation of specific IgE sensitization between birch pollen, soy and apple allergens indicates pollen-food allergy syndrome among birch pollen allergic patients in northern China
}

\author{
Guo-dong $\mathrm{HAO}^{1}$, Yi-wu ZHENG ${ }^{\dagger+2}$, Zhi-xiang $\mathrm{WANG}^{1}$, Xing-ai $\mathrm{KONG}^{1}$, \\ Zhi-jing SONG ${ }^{1}, \mathrm{Xu}$-xin $\mathrm{LAI}^{2}$, Michael D. SPANGFORT ${ }^{2}$ \\ ( ${ }^{I}$ Department of Allergy, Tangshan Gongren Hospital, Tangshan 063000, China) \\ ( ${ }^{2}$ ALK China Research, ALK, Guangzhou 510300, China) \\ †E-mail: Yiwu.Zheng@alk.net \\ Received Nov. 11, 2015; Revision accepted Jan. 17, 2016; Crosschecked Apr. 15, 2016
}

\begin{abstract}
Background: Birch pollen sensitization and associated pollen-food syndrome among Chinese allergic patients have not been investigated. Methods: Sera from 203 allergic patients from the northern part of China and collected during February to July 2014 were investigated. Specific immunoglobulin E (IgE) against birch pollen extract Bet $v$ and major birch pollen allergen Bet $v 1$ were measured using the ADVIA Centaur. The presence of major apple allergen Mal d 1 and soy bean allergen Gly m 4 specific IgE was measured by ImmunoCAP 100. Results: Among the 203 sera, 34 sera (16.7\%) had specific IgE to Bet $v$ and of these, 28 sera (82.4\%) contained Bet $v$ 1-specific IgE. Among the 28 sera with Bet v 1-specific IgE, 27 sera (96.4\%) contained Mal d 1-specific IgE and 22 sera (78.6\%) contained Gly $\mathrm{m}$ 4-specific IgE. Of the 34 Bet v-positive sera, 6 sera (17.6\%) contained no specific $\lg$ E for Bet v 1, Mal d 1, or Gly $\mathrm{m} 4$. Almost all Bet v-positive sera were donated during the birch pollen season. Conclusions: The prevalence of birch allergy among patients visiting health care during pollen season can be as high as $16.7 \%$ in Tangshan City. The majority of Chinese birch allergic patients are IgE-sensitized to the major birch pollen allergen Bet $v 1$ as well as to the major apple allergen Mal d 1 and soy bean allergen Gly $\mathrm{m} \mathrm{4}$. A relatively high number of patients $(17.6 \%)$ are IgE-sensitized to birch pollen allergen(s) other than Bet $v 1$. The high prevalence of specific lgE to Mal $\mathrm{d} 1$ and Gly $\mathrm{m} 4$ among Bet $v$ 1-sensitized patients indicates that pollen-food allergy syndrome could be of clinical relevance in China.
\end{abstract}

Key words: Apple, Birch, Cross-reaction, Pollen-food allergy, Soy, Specific immunoglobulin E (IgE) http://dx.doi.org/10.1631/jzus.B1500279

CLC number: R593.2

\section{Introduction}

Birch trees, Betula, grow in the temperate climate zone of the northern hemisphere and release large amounts of pollen during spring. Exposure to birch pollen allergens is a major reason of allergic rhinitis in Europe and one of the most frequent triggers of respiratory disease among European patients

\footnotetext{
* Corresponding author

(D) ORCID: Yi-wu ZHENG, http://orcid.org/0000-0002-2898-7842 (C) Zhejiang University and Springer-Verlag Berlin Heidelberg 2016
}

(Eriksson et al., 1998; Kampe et al., 2010; Caillaud et al., 2014). Birch pollen allergy and sensitization have not been as well studied in China mainly due to lack of specific diagnostic reagents. The major allergen of birch pollen is a $17-\mathrm{kDa}$ protein called Bet $\mathrm{v} 1$ (Ipsen and Løwenstein, 1983; Gajhede et al., 1996). Although European birch allergic patients may occasionally react to other allergens, in birch-rich areas of Scandinavia over $95 \%$ of birch pollen allergic patients display immunoglobulin E (IgE)-binding to Bet $\mathrm{v} 1$, while over $60 \%$ react exclusively to this allergen (Movérare et al., 2002). 
Up to $70 \%$ of birch pollen allergic individuals who experience seasonal rhinoconjunctivitis and/or asthma report having mucosal symptoms after consuming raw fruits and vegetables (Hofmann and Burks, 2008). The symptoms from this so called pollen-food allergy syndrome are often mild and self-resolving (Ma et al., 2003). However, severe systemic effects have been reported and can occur upon food consumption outside the pollen season (Katelaris, 2010; Rashid et al., 2011). The immunologic basis for the clinical reactions is considered to be due to cross-reacting IgE antibodies that are specific to birch pollen allergens, in particular Bet $\mathrm{v} 1$, but that can also recognize Bet $\mathrm{v}$ 1-homologous allergens from fruits and vegetables (Holm et al., 2001; Mittag et al., 2004; Tolkki et al., 2013). In a study evaluating severe oral allergy syndrome and anaphylactic reactions caused by a Bet $\mathrm{v}$ 1-related protein in soy bean (Glycine max), Gly m 4/SAM22, immediate-type allergic symptoms in patients with birch pollen allergy after ingestion of soy proteincontaining food items were reported to occur (KleineTebbe et al., 2002).

Birch pollen sensitization and pollen-food allergy syndrome are believed to be common in northern China. However, due to the lack of diagnostic tools and specific reagents, the prevalence of birch pollen sensitization has seldom been reported and the specific IgE correlation between birch pollen and food/vegetable allergens in China has not been investigated in detail. In this retrospective study, we investigated the prevalence and correlations of birch pollen extract and major birch allergen sensitization as well as the specific IgE correlation with the major apple allergen Mal $\mathrm{d} 1$ and soy bean allergen Gly $\mathrm{m} 4$. The study was performed using sera collected from allergic patients in the city of Tangshan (China).

\section{Materials and methods}

There were 203 subjects included in this study (5-66 years old) with a clinical history of allergic rhinitis/asthma. The subjects attended the Department of Allergy, Tangshan Gongren Hospital (Tangshan, China), from February to July 2014. The city of Tangshan is approximately $149 \mathrm{~km}$ east by southeast of Beijing with a population of 7.5 million inhabitants located in the northeastern Hebei Province. All subjects donated blood for specific IgE tests and serum samples were stored at $-20^{\circ} \mathrm{C}$ before measurement. All subjects or guardians provided informed consent.

Specific IgE concentrations against birch pollen extract Bet $\mathrm{v}$ and major birch pollen allergen Bet $\mathrm{v} 1$ were measured using the ADVIA Centaur (Siemens Medical Solutions, Diagnostics, NY, USA). The allergens, calibrators, controls, and universal reagent packs were from ALK (Hørsholm, Denmark). Major apple recombinant allergen rMal d 1 and soy bean recombinant allergen rGly $\mathrm{m} 4$ specific IgE were measured by the ImmunoCAP 100 fluorescence enzyme immunoassay system (Thermo Fisher, Uppsala, Sweden). The Centaur system was calibrated against ImmunoCAP. The specific IgE results of ADVIA Centaur and ImmunoCAP 100 have been shown to be comparable (Petersen et al., 2004). A cut-off value of $0.35 \mathrm{kU} / \mathrm{L}$ for specific IgE was regarded as a positive result $(<0.35 \mathrm{kU} / \mathrm{L}$, Class 0 ; $0.35-0.7 \mathrm{kU} / \mathrm{L}$, Class 1 ; 0.7-3.5 kU/L, Class 2; 3.5-17.5 kU/L, Class 3; 17.5-50 kU/L, Class 4; 50-100 kU/L, Class 5; $>100 \mathrm{kU} / \mathrm{L}$, Class 6).

The linear regression was plotted and $P$-value was calculated at $95 \%$ confidence intervals using Graph Pad Prism Version 6.00 (GraphPad Software, Inc., USA).

\section{Results}

A total of 203 serum samples collected during the period February to July, 2014 were retrospectively tested for specific IgE against Bet $\mathrm{v}$ and Bet $\mathrm{v} 1$. Among the 203 sera, 34 sera (16.7\%) had specific IgE to Bet $\mathrm{v}$ and of these, 28 sera $(82.4 \%)$ contained Bet $\mathrm{v} 1$ specific IgE (Table 1). The majority of birch allergen sera had specific $\operatorname{IgE}$ levels corresponding to ImmunoCAP Classes 3 and 4 (Fig. 1) and were detected in sera from patients attending the clinic during the birch pollen season (April to May). The correlation of specific $\operatorname{IgE}$ between Bet $\mathrm{v}$ and Bet $\mathrm{v} 1$ was high $\left(P<0.0001, R^{2}=0.98\right)$. All patients' sera with specific IgE to Bet $v 1$ had specific IgE antibodies against Bet v. Only 6 patients $(17.6 \%)$ with Bet vspecific IgE were negative to Bet $v 1$. Three of these sera had Bet v-specific IgE of Class 3 and the other three had specific IgE of Classes 1 and 2. 
Table 1 Specific IgE results against Bet $v$, Bet $v$ 1, Mal d 1 and rGly $\mathrm{m} 4$ in 34 birch pollen allergic patients

\begin{tabular}{|c|c|c|c|c|}
\hline $\begin{array}{l}\text { Patient } \\
\text { No. }\end{array}$ & $\begin{array}{c}\text { Bet v IgE } \\
(\mathrm{kU} / \mathrm{L})\end{array}$ & $\begin{array}{c}\text { Bet v } 1 \text { IgE } \\
(\mathrm{kU} / \mathrm{L})\end{array}$ & $\begin{array}{c}\text { Mal d 1 IgE } \\
(\mathrm{kUA} / \mathrm{L})\end{array}$ & $\begin{array}{c}\text { rGly m } 4 \text { IgE } \\
\text { (kUA/L) }\end{array}$ \\
\hline 1 & 135.33 & 96.77 & 34.40 & 17.60 \\
\hline 2 & 110.40 & 86.53 & 33.50 & 28.20 \\
\hline 3 & 67.25 & 53.76 & 27.90 & 28.00 \\
\hline 4 & 46.84 & 24.98 & 21.70 & 2.12 \\
\hline 5 & 76.86 & 59.89 & 18.60 & 4.88 \\
\hline 6 & 48.69 & 28.94 & 17.70 & 0.36 \\
\hline 7 & 39.10 & 37.74 & 15.80 & 4.87 \\
\hline 8 & 39.17 & 28.63 & 11.20 & 11.60 \\
\hline 9 & 59.95 & 44.80 & 9.49 & 5.74 \\
\hline 10 & 39.36 & 27.69 & 9.01 & 1.66 \\
\hline 11 & 90.81 & 68.88 & 7.26 & 0.02 \\
\hline 12 & 42.33 & 31.21 & 6.94 & 7.70 \\
\hline 13 & 28.84 & 28.13 & 5.62 & 2.44 \\
\hline 14 & 25.32 & 22.03 & 4.23 & 3.97 \\
\hline 15 & 26.15 & 21.73 & 3.48 & 0.01 \\
\hline 16 & 22.86 & 20.46 & 3.46 & 4.59 \\
\hline 17 & 12.83 & 10.17 & 3.25 & 1.70 \\
\hline 18 & 33.34 & 25.85 & 2.65 & 1.01 \\
\hline 19 & 56.24 & 32.85 & 2.59 & 1.44 \\
\hline 20 & 4.53 & 2.82 & 2.39 & 0.26 \\
\hline 21 & 10.22 & 8.84 & 2.38 & 1.35 \\
\hline 22 & 43.42 & 26.4 & 2.21 & 7.68 \\
\hline 23 & 15.64 & 11.68 & 1.83 & 0.01 \\
\hline 24 & 5.45 & 4.39 & 1.78 & 0.12 \\
\hline 25 & 7.76 & 6.24 & 1.57 & 0.90 \\
\hline 26 & 16.11 & 13.24 & 1.19 & 3.30 \\
\hline 27 & 17.39 & 14.47 & 0.66 & 0.48 \\
\hline 28 & 0.37 & 0.01 & 0.12 & 0.10 \\
\hline 29 & 3.00 & 2.10 & 0.11 & 0.01 \\
\hline 30 & 8.48 & 0.01 & 0.06 & 0.01 \\
\hline 31 & 14.63 & 0.01 & 0.04 & 0.01 \\
\hline 32 & 2.01 & 0.01 & 0.02 & 0.01 \\
\hline 33 & 0.78 & 0.01 & 0.01 & 0.01 \\
\hline 34 & 13.27 & 0.01 & 0.01 & 0.01 \\
\hline
\end{tabular}

Bet $\mathrm{v} 1$ was tested on ADVIA Centaur. Mal d 1 and rGly $\mathrm{m} 4$ were measured on ImmunoCAP 100

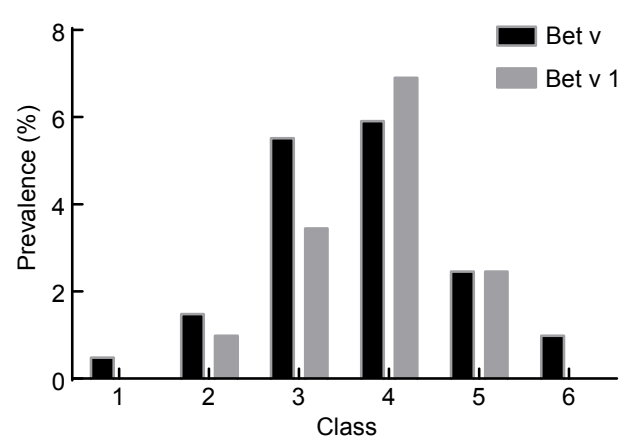

Fig. 1 Prevalence of specific IgE reactivity (positive percentage in different classes) to Bet $v$ and Bet $v 1$ among 203 sera Class 1: $0.35-0.7 \mathrm{kU} / \mathrm{L}$; Class 2: $0.7-3.5 \mathrm{kU} / \mathrm{L}$; Class 3: 3.5-17.5 kU/L; Class 4: $17.5-50 \mathrm{kU} / \mathrm{L}$; Class 5: 50-100 kU/L; Class 6: $>100 \mathrm{kU} / \mathrm{L}$
To investigate the relation between Bet $\mathrm{v} 1$ and apple allergen, Mal d 1 sensitization, specific $\operatorname{IgE}$ against recombinant Mal d 1 was measured in the 28 samples positive to Bet $\mathrm{v} 1$ and in an additional 37 samples negative to Bet $v 1$. Of the 28 serum samples containing Bet $\mathrm{v}$ 1-specific IgE, 27 samples (96.4\%) also contained rMal d 1-specific IgE with a highest level of $34.4 \mathrm{kUA} / \mathrm{L}$. All Bet v 1-negative samples were also negative to rMal d 1-specific IgE. In the same serum sample, the rMal d 1-specific IgE level was never higher than the level of Bet $v$ 1-specific IgE. There was a high correlation between Bet $\mathrm{v} 1$ and rMal d 1-specific $\operatorname{IgE}\left(P<0.0001, R^{2}=0.78\right.$; Fig. 2a).

Likewise, to investigate the relation between Bet $\mathrm{v} 1$ and soy bean allergen Gly $\mathrm{m} 4$ sensitization, specific $\mathrm{IgE}$ against rGly $\mathrm{m} 4$ was measured in the 28 samples positive to Bet $\mathrm{v} 1$ and in the 37 samples negative to Bet $v 1$. Of the 28 serum samples containing Bet $v 1$ specific IgE, 22 samples (78.6\%) also contained rGly $m$ 4-specific IgE with a highest level of $28.2 \mathrm{kUA} / \mathrm{L}$. All Bet v 1-negative samples were also negative to rGly $\mathrm{m} 4 \mathrm{IgE}$. In the same serum sample, the rGly $\mathrm{m}$ 4-specific IgE level was never higher than
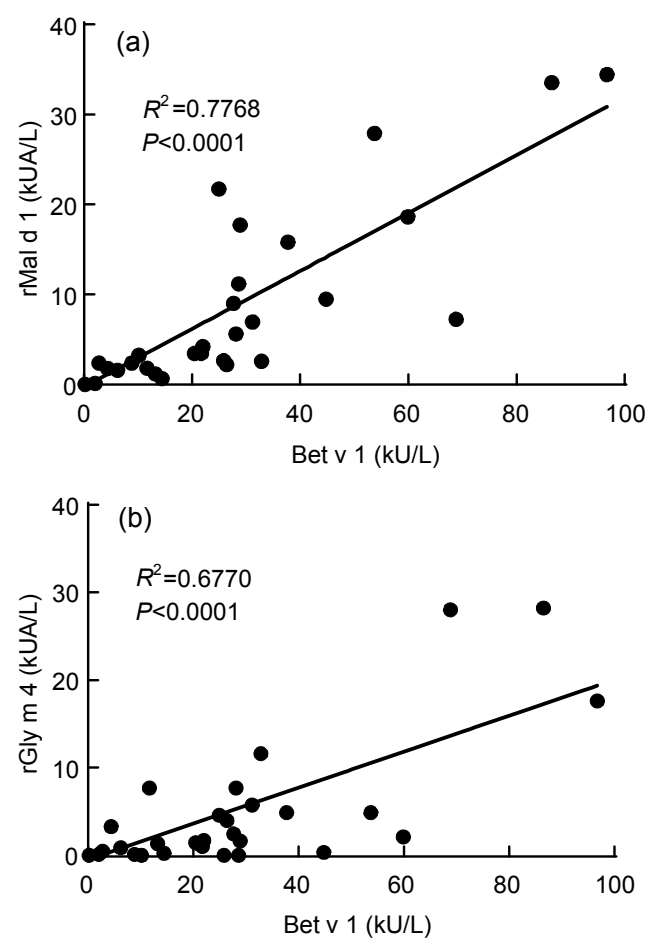

Fig. 2 Correlation between specific IgE against Bet $v 1$ and rMal $d 1$ (a) as well as Bet $v 1$ and rGly $m 4$ (b) among 65 patients (28 Bet $v$ 1-positive sera +37 Bet $v$ 1-negative sera) Bet $\mathrm{v} 1$ was tested on ADVIA Centaur. rMal d 1 and rGly m 4 were measured on ImmunoCAP 100 
the level of Bet $\mathrm{v}$ 1-specific IgE but a few sera had higher IgE levels compared to Mal d 1. There was a high correlation between Bet $\mathrm{v} 1$ and rGly $\mathrm{m}$ 4specific $\operatorname{IgE}\left(P<0.0001, R^{2}=0.68\right.$; Fig. $\left.2 b\right)$.

\section{Discussion}

In a nationwide, year-long study, the skin prick test (SPT) prevalence of tree pollen, including Bet $\mathrm{v}$, sensitization among 6304 Chinese allergic patients was reported to be $2 \%$ (Li et al., 2009). Geographical differences exist and the SPT prevalence is $4 \%$ in northern parts of China and $2.7 \%$ in the south $(\mathrm{Li}$ et al., 2009; Hong et al., 2011). However, as demonstrated in this work, during the birch pollen season about $16.7 \%$ of the patients attending the allergy department in Tangshan City, northern China showed specific IgE-positive reaction to birch pollen allergens. This is in agreement with a previous study from this geographical area showing a prevalence of birch pollen-induced allergic rhinitis of $15 \%-22 \%$ (Wang et al., 2012).

In this study, $82.4 \%$ of birch pollen sensitized patients also showed IgE-binding to Bet $\mathrm{v} 1$ defining Bet $\mathrm{v} 1$ as the major birch pollen allergen among the Chinese population. There were also $17.6 \%$ of birch pollen-sensitized subjects that did not show any specific IgE-binding to Bet $v 1$. This may be due to sensitization towards other minor birch allergens, for instance Bet v 2. Specific IgE-binding to Bet v 2 with a prevalence of around $2 \%$ has previously been demonstrated by allergen micro-array analyses of 100 Chinese allergic sera (Zheng et al., 2011).

The first food allergen extract reported to show cross-reactivity to birch pollen was apple extract (Lahti et al., 1980) and it has been shown that around $28 \%$ patients with allergic rhinitis and monosensitized to birch pollen experience symptoms of pollen-food allergy upon consumption of apple (Tolkki et al., 2013). The amino acid sequences of the major allergens Bet $\mathrm{v} 1$ and the homologous apple allergen Mal d 1 are close to $50 \%$ identical (Holm et al., 2001). The molecular structures of Bet $\mathrm{v} 1$ and Mal d 1 are very similar, resulting in the appearance of common IgE-binding epitopes (Schöning et al., 1996; Holm et al., 2011). In addition, birch pollen and apple share other homologous minor allergens with relatively low prevalence of specific IgE sensitization (Hauser et al., 2010). We investigated Mal d 1 sensitization among Bet $\mathrm{v} 1$-positive patients and clearly demonstrated that $96.4 \%$ of patients with specific $\operatorname{IgE}$ to Bet $v 1$ also had specific IgE to rMal d 1 at clinically relevant levels. Since primary sensitization to apple is uncommon, it indicates strongly that birch pollen-food allergy syndrome could be of clinical importance among Chinese birch pollen allergy patients.

Soy allergy conventionally is characterized by IgE sensitization to storage proteins like Gly $\mathrm{m} 5$, Gly m 6 (Holzhauser et al., 2009; Ito et al., 2011), or Gly $\mathrm{m} 8$ that are $2 \mathrm{~S}$ albumins (Ebisawa et al., 2013). The association between birch and soy allergy was first reported by Kleine-Tebbe et al. (2002) describing that patients with birch pollen allergy had allergic reactions to a soy-containing dietary product. In contrast to conventional soy allergy, tree pollen-related Gly $\mathrm{m} 4$ allergy seems to be associated with reactions only to mildly processed soy (often soy milk) (Kosma et al., 2011; Fukutomi et al., 2012), which is possibly related to the structural stability of Gly $\mathrm{m} 4$. The amino acid sequence identity between Gly $\mathrm{m} 4$ and Bet $\mathrm{v} 1$ is $53 \%$ and allergic reactions after ingestion of soy bean have been shown to be caused by Bet $\mathrm{v} 1$ specific $\operatorname{IgE}$ antibodies cross-reacting with Gly $\mathrm{m} 4$ (Kleine-Tebbe et al., 2002). In our study, close to $80 \%$ of birch allergic patients were also sensitized to rGly $\mathrm{m} 4$. The clinical relevance of this finding needs to be established since $\operatorname{IgE}$ sensitization to both Bet $\mathrm{v} 1$ and Gly $\mathrm{m} 4$ can cause severe pollen-food allergy syndrome reactions, although not all Gly $\mathrm{m}$ 4sensitized patients show clinical symptoms of soy allergy (Mittag et al., 2004). Unfortunately, lack of detailed patient clinical history and profiles in this retrospective study as well as access to specific food-allergen reagents prevented further investigation and more detailed studies are needed addressing the prevalence and clinical manifestations of pollen-food allergy syndrome in China.

In summary, the prevalence of birch polleninduced allergy seems to be high during the pollen season in northern China. Similar to other populations, the majority of Chinese birch allergic patients are sensitized to the major birch pollen allergen Bet $\mathrm{v} 1$. A relatively large amount of patients $(17.6 \%)$ are $\mathrm{IgE}-$ sensitized to birch pollen allergen(s) other than Bet $\mathrm{v} 1$. 
The high prevalence of specific IgE to rMal d 1 and rGly $\mathrm{m} 4$ among Bet $\mathrm{v} 1$-sensitized patients indicates that birch pollen-food allergy syndrome may be of clinical relevance in China and require more detailed investigation. Evaluation of pollen-food allergy syndrome and allergen avoidance recommendations should be considered in the clinical management and recommendations to patients with confirmed birch pollen allergy.

\section{Acknowledgements}

The authors are grateful to Tian-tian LIU and Hai-feng ZHONG from ALK (Guangzhou, China) for their skilled experimental performance.

\section{Compliance with ethics guidelines}

Guo-dong HAO, Yi-wu ZHENG, Zhi-xiang WANG, Xing-ai KONG, Zhi-jing SONG, Xu-xin LAI, and Michael D. SPANGFORT declare that they have no conflict of interest.

All procedures followed were in accordance with the ethical standards of the responsible committee on human experimentation (institutional and national) and with the Helsinki Declaration of 1975, as revised in 2008 (5). Informed consent was obtained from all patients for being included in this study.

\section{References}

Caillaud, D., Martin, S., Segala, C., et al., 2014. Effects of airborne birch pollen levels on clinical symptoms of seasonal allergic rhinoconjunctivitis. Int. Arch. Allergy Immunol., 163(1):43-50. http://dx.doi.org/10.1159/000355630

Ebisawa, M., Brostedt, P., Sjolander, S., et al., 2013. Gly m 2S albumin is a major allergen with a high diagnostic value in soybean-allergic children. J. Allergy Clin. Immunol., 132(4):976-978.

http://dx.doi.org/10.1016/j.jaci.2013.04.028

Eriksson, N.E., Holmen, A., Moller, C., et al., 1998. Sensitization according to skin pick testings in atopic patients with asthma or rhinitis at 24 allergy clinics in Northern Europe and Asia. Allergol. Int., 47(3):187-196. http://dx.doi.org/10.2332/allergolint.47.187

Fukutomi, Y., Sjolander, S., Nakazawa, T., et al., 2012. Clinical relevance of IgE to recombinant Gly $\mathrm{m} 4$ in the diagnosis of adult soybean allergy. J. Allergy Clin. Immunol., 129(3):860-863. http://dx.doi.org/10.1016/j.jaci.2012.01.031

Gajhede, M., Osmark, P., Poulsen, F.M., et al., 1996. X-ray and NMR structure of Bet $\mathrm{v}$ 1, the origin of birch pollen allergy. Nat. Struct. Biol., 3(12):1040-1045. http://dx.doi.org/10.1038/nsb1296-1040

Hauser, M., Roulias, A., Ferreira, F., et al., 2010. Panallergens and their impact on the allergic patient. Allergy Asthma Clin. Immunol., 6(1):1. http://dx.doi.org/10.1186/1710-1492-6-1
Hofmann, A., Burks, W.A., 2008. Pollen food syndrome: update on the allergens. Curr. Allergy Asthma Rep., 8(5): 413-417. http://dx.doi.org/10.1007/s11882-008-0080-0

Holm, J., Baerentzen, G., Gajhede, M., et al., 2001. Molecular basis of allergic cross-reactivity between group 1 major allergens from birch and apple. J. Chromatogr. B Biomed. Sci. Appl., 756(1-2):307-313. http://dx.doi.org/10.1016/S0378-4347(01)00089-5

Holm, J., Ferreras, M., Ipsen, H., et al., 2011. Epitope grafting, re-creating a conformational Bet $\mathrm{v} 1$ antibody epitope on the surface of the homologous apple allergen Mal d 1.J. Biol. Chem., 286(20):17569-17578. http://dx.doi.org/10.1074/jbc.M110.194878

Holzhauser, T., Wackermann, O., Ballmer-Weber, B.K., et al., 2009. Soybean (Glycine max) allergy in Europe: Gly m 5 ( $\beta$-conglycinin) and Gly m 6 (glycinin) are potential diagnostic markers for severe allergic reactions to soy. $J$. Allergy Clin. Immunol., 123(2):452-458. http://dx.doi.org/10.1016/j.jaci.2008.09.034

Hong, H., Fan, Y., Yang, Q., et al., 2011. A cohort investigation of the allergen and pathogenesis in the patients with allergic rhinitis from three hospital of Guangzhou Province. J. Clin. Otorhinolaryngol. Head Neck Surg., 25(23): 1064-1067 (in Chinese).

Ipsen, H., Løwenstein, H., 1983. Isolation and immunochemical characterization of the major allergen of birch pollen (Betula verrucosa). J. Allergy Clin. Immunol., 72(2):150-159. http://dx.doi.org/10.1016/0091-6749(83)90523-7

Ito, K., Sjolander, S., Sato, S., et al., 2011. IgE to Gly m 5 and Gly $\mathrm{m} 6$ is associated with severe allergic reactions to soybean in Japanese children. J. Allergy Clin. Immunol., 128(3):673-675. http://dx.doi.org/10.1016/j.jaci.2011.04.025

Kampe, M., Janson, C., Stalenheim, G., et al., 2010. Experimental and seasonal exposure to birch pollen in allergic rhinitis and allergic asthma with regards to the inflammatory response. Clin. Respir. J., 4(1):37-44. http://dx.doi.org/10.1111/j.1752-699X.2009.00140.x

Katelaris, C.H., 2010. Food allergy and oral allergy or pollenfood syndrome. Curr. Opin. Allergy Clin. Immunol., 10(3):246-251. http://dx.doi.org/10.1097/ACI.0b013e32833973fb

Kleine-Tebbe, J., Wangorsch, A., Vogel, L., et al., 2002. Severe oral allergy syndrome and anaphylactic reactions caused by a Bet v 1-related PR-10 protein in soybean, SAM22. J. Allergy Clin. Immunol., 110(5):797-804. http://dx.doi.org/10.1067/mai.2002.128946

Kosma, P., Sjolander, S., Landgren, E., et al., 2011. Severe reactions after the intake of soy drink in birch pollenallergic children sensitized to Gly m 4. Acta Paediatr., 100(2):305-306. http://dx.doi.org/10.1111/j.1651-2227.2010.02049.x

Lahti, A., Bjorksten, F., Hannuksela, M., 1980. Allergy to birch pollen and apple, and cross-reactivity of the allergens studied with the RAST. Allergy, 35(4):297-300. 
http://dx.doi.org/10.1111/j.1398-9995.1980.tb01770.x

Li, J., Sun, B., Huang, Y., et al., 2009. A multicenter study assessing the prevalence of sensitizations in patients with asthma and/or rhinitis in China. Allergy, 64(7):1083-1092. http://dx.doi.org/10.1111/j.1398-9995.2009.01967.x

Ma, S., Sicherer, S.C., Nowark-Wegrzyn, A., 2003. A survey on the management of pollen-food allergy syndrome in allergy practices. J. Allergy Clin. Immunol., 112(4):784-788. http://dx.doi.org/10.1016/S0091-6749(03)02008-6

Mittag, D., Vieths, S., Vogel, L., et al., 2004. Soybean allergy in patients allergic to birch pollen: clinical investigation and molecular characterization of allergens. J. Allergy Clin. Immunol., 113(1):148-154. http://dx.doi.org/10.1016/j.jaci.2003.09.030

Movérare, R., Westritschnig, K., Svensson, M., et al., 2002. Different IgE reactivity profiles in birch pollen sensitive patients from six European populations revealed by recombinant allergens: an imprint of local sensitization. Int. Arch. Allergy Immunol., 128(4):325-335. http://dx.doi.org/10.1159/000063855

Petersen, A.B., Gudmann, P., Milvang-Gronager, P., et al., 2004. Performance evaluation of a specific IgE assay developed for the ADVIA centaur immunoassay system. Clin. Biochem., 37(10):882-892. http://dx.doi.org/10.1016/j.clinbiochem.2004.06.010

Rashid, R.S., Smith, K.A., Nambiar, K.Z., et al., 2011. Pollenfood syndrome is related to Bet v 1/PR10 protein sensitization, but not all patients have spring sensitization. Allergy, 66(10):1391-1392. http://dx.doi.org/10.1111/j.1398-9995.2011.02618.x

Schöning, B., Ziegler, W.H., Vieths, S., et al., 1996. Apple allergy: the cDNA sequence of the major allergen of apple, determined by performing PCR with a primer based on the N-terminal amino acid sequence, is highly homologous to the sequence of the major birch pollen allergen. $J$. Sci. Food Agric., 71(4):475-482.

http://dx.doi.org/10.1002/(SICI)1097-0010(199608)71:4<47 5::AID-JSFA603>3.0.CO;2-C
Tolkki, L., Alanko, K., Petman, L., et al., 2013. Clinical characterization and IgE profiling of birch (Betula verrucosa) - allergic individuals suffering from allergic reactions to raw fruits and vegetables. J. Allergy Clin. Immunol. Pract., 1(6):623-631.

http://dx.doi.org/10.1016/j.jaip.2013.07.010

Wang, Z.H., Lin, W.S., Wang, L., et al., 2012. Distribution of allergens in patients with allergic rhinitis in Hebei villagers and Tianjin citizens. J. Clin. Otorhinolaryngol. Head Neck Surg., 47(10):809-812 (in Chinese).

Zheng, Y., Li, J., Lai, X., et al., 2011. Allergen micro-array detection of specific IgE reactivity in Chinese allergic patients. China Med. J., 124(24):4350-4354.

\section{中文概要}

题 目: 桦树花粉、大豆和苹果过敏原之间高免疫球蛋白 E 相关性表明中国北方地区桦树花粉过敏患者 很可能同时患有花粉-食物综合征

目 的: 研究中国北方地区桦树花粉过敏及花粉-食物过 敏综合征。

创新点: 国内首次研究花粉-食物过敏综合征, 为中国北 方地区此类患者的诊断和治疗提出了新思路。

方 法: 采集临床中过敏患者血清, 检测桦树花粉及其主 要过敏原特异性免疫球蛋白 $\mathrm{E}(\mathrm{IgE})$, 同时检 测大豆和苹果过敏原的特异性 IgE, 并评价其相 关性。

结 论: 中国北方地区桦树花粉季节对此花粉过敏的患者 有 $16.7 \%$ 以上, 主要是对桦树花粉第一组过敏原 致敏。这些患者大多数同时对大豆和苹果的主要 过敏原过敏, 这种特异性 IgE 高相关性说明临床 上存在花粉一食物过敏综合征。

关键词: 桦树; 大豆; 苹果; 特异性 IgE; 花粉-食物过敏 综合征 